\title{
Filosofia da educação: considerações críticas conceituais à reforma educacional dos cursos de pedagogia
}

\author{
Gilson Luís Voloski*
}

\section{Resumo}

Este estudo desenvolve considerações críticas aos conceitos de teoria e prática da avaliação diagnóstica da reforma educacional dos cursos de pedagogia. A análise parte da constatação de que os cursos são insuficientes na formação prática de ensino. Não concorda com a aplicabilidade como critério de validade da teoria. Reconhece que é pertinente à melhoria do "quê" e do "como ensinar", porém, não pode ser exclusivo, pois reduziria a teoria pedagógica apenas aos seus aspectos de ensino. Isso implicaria em instrumentalizar ou secundarizar os fundamentos teóricos, entre eles, o da filosofia da educação. $O$ desafio é justificar um conceito mais amplo de prática, que garanta a legitimidade de um núcleo de autonomia da teoria. Com isso, busca argumentar em favor do duplo caráter da teoria: pertence à sociedade e é autônoma. A teoria pedagógica reproduz a sociedade e, também, resiste a essa como formação cultural. Portanto, a relação com a prática apresenta dois sentidos: visa à unidade de identidade no ensino e a um núcleo de tensão aberta à crítica e à autocrítica.

Palavras-chave: Filosofia da educação. Reforma educacional. Teoria e práxis.

\section{Introdução}

Este texto tem por objetivo desenvolver algumas considerações críticas aos conceitos de teoria e prática da avaliação diagnóstica da reforma educacional nos cursos de pedagogia,${ }^{1}$ tendo como foco de análise a posição curricular da filosofia da educação. A atual reforma educacional é um processo abrangente, desencadeado na década de 1990. Em relação à legislação brasileira, o marco é a promulgação, em dezembro de 1996, da Lei de Diretrizes e Bases da Educação Nacional, Lei n⿳o 
9.394/1996 (BRASIL, 1996). Em seguida, leis complementares expandiram a reforma em todos os níveis da educação. Inicialmente, priorizou-se a universalização do ensino fundamental com a criação do Fundef, ${ }^{2}$ passando pela expansão da educação infantil e do ensino médio, pelo Fundeb, ${ }^{3}$ chegando ao ensino superior, com o Programa Universidade para Todos.

Na última década, a ênfase deslocou-se para a problemática da qualidade da educação básica. Entre outros aspectos limitantes, evidenciou-se a pertinência da formação de professores. O embasamento legal está na Resolução $\mathrm{CNE} / \mathrm{CP} \mathrm{n}^{\circ}$ 1/2002, de 18 de fevereiro de 2002, que institui as Diretrizes Curriculares Nacionais para a Formação de Professores da Educação Básica, em nível superior, no curso de licenciatura, de graduação plena (BRASIL, 2002). Em maio de 2006, a reforma chega ao curso de pedagogia com a Resolução CNE/CP nº 1/2006, que institui as Diretrizes Curriculares Nacionais para o Curso de Graduação em Pedagogia (BRASIL, 2006).

O Departamento de Pesquisas Educacionais da Fundação Carlos Chagas desenvolveu pesquisas de estudos de currículos dos cursos de licenciaturas. Como ponto de partida da reflexão sobre a relação teoria e prática na formação do pedagogo, concentre-se nos dados diagnósticos apresentados em dois textos: Avaliação dos currículos de formação de professores para o ensino fundamental (GATTI et al., 2009) e do livro Formação de professores para o ensino fundamental: estudo de currículo das licenciaturas em pedagogia, língua portuguesa, matemática e ciência biológica (GATTI; NUNES, 2009). A demarcação sobre os currículos de pedagogia justifica-se pela maior presença da filosofia da educação nesses cursos do que em outras licenciaturas.

Uma parte da pesquisa da FCC consistiu em confrontar as novas diretrizes da Resolução CNE/CP no 1/2006 com os projetos pedagógicos e as ementas das disciplinas dos cursos presenciais de pedagogia. Desse modo, procurou-se evidenciar a distância entre o que determina a legislação e o que está sendo "proposto como formação nas instituições de ensino superior, identificando ênfases que lhes estão sendo atribuídas e a adequação às demandas profissionais" (GATTI et al., 2009, p. 217).

Delimito a análise textual a partir das seguintes perguntas: quais os contornos dos conceitos de teoria e prática que aparecem na análise dos currículos dos cursos de pedagogia? Como se manifesta a concepção de relação entre eles? Quais as implicações para o campo das disciplinas curriculares dos fundamentos teóricos da educação e do processo formativo? 


\section{Abrangência dos estudos de currículos de pedagogia}

A análise documental da Fundação Carlos Chagas concentrou-se em 71cursos de pedagogia, no período de 2004 a 2006, distribuídos entre instituições públicas (federal, estadual e municipal) e instituições privadas das cinco regiões do Brasil. Outras fontes utilizadas foram os dados do Instituto Nacional de Estudos e Pesquisas Educacionais Anísio Teixeira, nos períodos de 2001, 2004 e 2006, e do Relatório Síntese do Exame Nacional de Desempenho dos Estudantes, de 2005.

Das amostragens dos cursos, foram listadas 3.513 disciplinas nas grades curriculares, agrupadas com referência aos três núcleos da Resolução CNE/CP $\mathrm{n}^{\mathrm{o}}$ 1/2006: 1) estudos básicos; 2) aprofundamentos e diversificação de estudos; 3) estudos integradores. Os núcleos foram subdivididos em sete categorias para a classificação das disciplinas. Segundo as pesquisadoras, elas seriam necessárias para interpretar "os vários aspectos da formação", ao mesmo tempo em que possibilitariam uma visão geral que "sinaliza a tendência formativa do conjunto dos cursos" em abrangência nacional (GATTI; NUNES, 2009, p. 19). As sete categorias são: 1) fundamentos teóricos da educação; 2) conhecimentos relativos aos sistemas educacionais; 3) conhecimentos relativos à formação profissional específica; 4) conhecimentos relativos a modalidades e nível de ensino específico: educação infantil, educação especial, educação de jovens e adultos, educação em contextos não escolares; 5) outros saberes; 6) pesquisa e trabalho de conclusão de curso; 7) atividades complementares, estágios.

No resultado da classificação, “[...] foram encontradas 3.107 disciplinas registradas como obrigatórias, excluindo-se as que se referem a estágios, o que sugere a possibilidade de pensar, em média, em 44 disciplinas obrigatórias por curso" (GATTI; NUNES, 2009, p. 21). As autoras sinalizam como positiva a variabilidade de disciplinas de um curso para o outro, pois isso expressa a diversidade vocacional de cada região. Porém, apontam como limite a fragmentação curricular.

\section{Da relação teoria e prática}

Depois da classificação das disciplinas curriculares em sete categorias, a análise converge para dois agrupamentos principais: de um lado, as disciplinas de caráter teórico e, de outro, as que teriam função prática específica.

A princípio, é identificado um equilíbrio nos currículos entre o conjunto de disciplinas teóricas e práticas: $26 \%$ de fundamentos teóricos da educação e $28 \%$ de formação profissional específica. Conforme Gatti e Nunes (2009, p. 20), o primeiro 
cumpre a função de embasar "teoricamente o aluno de Pedagogia", enquanto no segundo "concentram-se as disciplinas que fornecem instrumental para atuação do professor". Nesse contexto, interpreto a palavra "instrumental" como um conjunto de conteúdos e procedimentos metodológicos (como veremos adiante, referente a "o quê" e a "como" ensinar) para o desempenho da atividade docente. Assim, o conceito de prática é recortado na dimensão procedimental de ensino.

$\mathrm{Na}$ sequência da análise, o equilíbrio entre os dois blocos de disciplinas (26\% e 28\%) cede em favor do caráter de fundamentos teóricos. Agregam-se a esse as disciplinas agrupadas nas categorias "outros saberes" e "atividades complementares”. Assim, o percentual de 26\% passa para 40\%. O desequilíbrio é apresentado de modo mais enfático no cômputo das horas dos cursos quando se referem em 70\%:

A proporção de horas dedicadas às disciplinas referentes à formação profissional específica é de $30 \%$, ficando $70 \%$ para outro tipo de matérias oferecidas nas instituições formadoras. Cabe a ressalva já feita na análise das ementas, segundo a qual, nas disciplinas de formação profissional, predominam os referenciais teóricos, seja de natureza sociológica, psicológica ou outros, com associação em poucos casos às práticas educacionais (GATTI; NUNES, 2009, p. 23-24).

A análise procura demonstrar, em percentual, que se fornece pouco de formação prática nos currículos. Inclusive, as disciplinas de "formação profissional", responsáveis por proporcionar o desenvolvimento de tais habilidades, manifestam predominância de fundamentos teóricos. Duas áreas das ciências da educação são mencionadas, sociologia e psicologia, mas não é citada diretamente a filosofia.

Com base nos dados percentuais, é possível afirmar que os cursos são mais teóricos do que práticos.

Nas ementas, observou-se um evidente desequilíbrio na relação teoria-prática, em favor dos tratamentos mais teóricos, de fundamentos e contextualização, e a escola, como instituição social e de ensino, é elemento quase ausente nas ementas, o que leva a pensar em uma formação de caráter mais abstrata, e pouco integrada ao contexto concreto onde o profissional-professor vai atuar (GATTI et al., 2009, p. 233).

$\mathrm{Na}$ interpretação das autoras sobre o núcleo de estudos básicos dos cursos de pedagogia, estabelecido pela Resolução CNE/CP no 1/2006, as palavras "aplicação" e "realização" são determinantes, como se observa no que segue:

O núcleo de estudos básicos é descrito, no referido documento, com a predominância da palavra aplicação e realização: "aplicação, em práticas educativas, de conhecimentos de processos de desenvolvimento de crianças..."; "aplicação de princípios, concepções e critérios oriundos de diferentes áreas de conhecimentos...”, sinalizando que os conteúdos desenvolvidos durante o curso devem ser estudados em uma vertente prática, aliada a seus fundamentos, para que se construam competências de aplicabilidade (GATTI et al., 2009, p. 232). 
O que implica estabelecer a aplicação e a realização como uma espécie de parâmetro para a teoria pedagógica? A palavra aplicação tem diversos sentidos, mas quando associada à realização pressupõe, no fim do processo, algo objetivado. Assim, o resultado pode tornar-se uma referência à avaliação e à melhoria. Nesse caso, a finalidade da relação é a identidade entre teoria e prática, entre planejamento e ação. Portanto, considerando que se trata de um conceito delimitado de prática, estabelecer a aplicação e a realização como critério de validade pode contribuir para a melhoria da dimensão procedimental de ensino.

No entanto, é imprescindível ressaltar que o conceito de prática é mais abrangente na teoria pedagógica. A própria Resolução CNE/CP nº 1/2006 tem outros aspectos do conceito de prática. ${ }^{4}$ No caso, a ela relaciona-se um núcleo teórico de princípios, normas e conceitos interpretativos e orientadores para a ação docente. No caráter ético-normativo, a prática tem seus fins na própria ação; e a teoria tem em si mesma um caráter prático (NOBRE, 2004, p. 8), o que extrapola qualquer classificação dicotômica bem como o critério de validade proposto.

Contudo, é prudente problematizar, igualmente, as possíveis implicações do outro extremo: até que ponto o critério da realização prática pode referendar o discurso teórico? Estabelecer como critério de validade o que se realiza não conduz a teoria pedagógica ao ajustamento da determinação social vigente? As pressuposições ético-epistemológicas da educação não são, essencialmente, discursos justificadores do sentido abrangente da própria educação? Assumo o pressuposto de que o critério de validade proposto pelas autoras é pertinente para a melhoria da prática de ensino escolar, mas deve-se evitar que se torne referência exclusiva para a teoria pedagógica, pois seria reduzi-la ao ensino.

\section{Da relação dos componentes didáticos}

A análise das ementas das disciplinas curriculares do curso de pedagogia, realizada pela Fundação Carlos Chagas, consistiu em observar a presença do "o quê" e do "como" ensinar. São componentes didáticos que se referem aos conteúdos específicos e às metodologias de ensino. Esses devem aparecer nas disciplinas de "formação profissional específica". No entanto, as autoras identificam pouca presença, como se observa no excerto a seguir:

[...] a ênfase das ementas, que registram preocupação com as justificativas sobre "o porquê" ensinar - o que, de certa forma, contribuiria para evitar que essas matérias se transformassem em meros receituários; entretanto, só de forma muito incipiente registram "o quê" e “como" ensinar (GATTI et al., 2009, p. 215). 
O ensino é composto também por outros componentes didáticos e, entre os principais, encontram-se "o porquê" e "o para quê" ensinar. O resultado da análise das ementas registra a presença predominante do "porquê", no sentido de uma "preocupação com as justificativas". O texto não realiza qualquer comentário direto sobre o "para quê". É possível observar que a leitura das pesquisadoras concentra-se nos aspectos do "como" e do "quê" ensinar. Esses componentes proporcionam o suporte instrumental para a atuação específica da docência. De outro modo, o isolamento desses componentes é compreensível apenas como delimitação de análise de uma pesquisa. No processo formativo, a desvinculação do "como" e do "quê" em relação ao "porquê" e ao "para quê" não deixa de trazer prejuízos à prática pedagógica, entre eles, a redução dos fins em meios eficientes.

O desafio apresentado pela pesquisa coordenada por Gatti, do qual não discordo, é recuperar os componentes didáticos do "quê" e do "como" ensinar nos currículos. Entretanto, outro aspecto, do mesmo desafio, é evitar que esse argumento não se torne uma justificativa de recuo do "porquê" e do "para quê" (ensinar, educar, formar), ${ }^{5}$ pois isso conduziria a uma polarização prática (TREVISAN, 2011, p. 204). Trata-se de um desafio importante, visto que a qualidade do processo formativo depende da mediação equilibrada desses elementos.

Amélia de Castro (1991) reconstrói, em linhas gerais, a constituição do campo de conhecimento da didática como um saber de fronteiras, por isso produtiva pelo diálogo entre diversas áreas de conhecimento afins.

É como decorrência desse conceito nuclear que se situam as inquietações da Didática atual. É esse conceito que é objeto de controvérsias teóricas, que às vezes levam a disputa ao campo interdisciplinar do "currículo", como que exigindo da Didática que proceda à sua invasão, já que o conteúdo do ensino - o "o quê" se ensina - tanto pode ser problema didático quanto curricular. Outras vezes leva a outro campo inter-relacionado, o da Psicologia do Desenvolvimento ou Aprendizagem, já que o êxito do processo de Ensino, aquilo mesmo que justifica tentá-lo, é a Aprendizagem. E, conforme a teoria surge todo o problema do desenvolvimento intelectual, afetivo, moral, social, igualmente interdisciplinar. Mais um problema de limites, e crucial, está nas outras questões: por que ensinar? E para quê? E chegamos aos limites da Filosofia da Educação, da Sociologia, da Política (CASTRO, 1991, p. 21).

É importante ressaltar que Castro publicou seu trabalho em 1991, com o título A trajetória histórica da didática, período de balanço da década de 1980, de expansão da pedagogia crítica e do recuo do tecnicismo. Vale a pena observar como a autora não menciona nada referente ao "como" ensinar. Para ela, a didática geral precisa, por sua própria natureza, dialogar com outras áreas de conhecimento. Como um saber de fronteiras, que nem sempre tem, com clareza, demarcadas as margens que o delimitam. Por isso, sugere como referência de demarcação entre a didática e as disciplinas de fundamentos teóricos da educação, as perguntas: "Por 
que ensinar?" e "Para que ensinar?". Essas perguntas marcariam os limites da relação dialógica com a filosofia da educação, a sociologia da educação e a política. A passagem citada retrata o quanto foi ampliado o conceito de didática naquela década, possivelmente como resistência à tentativa de sua redução a mero meio ou simples técnica de aprendizagem. Concordo com a autora que a contribuição da filosofia da educação vincula-se, principalmente, aos componentes didáticos do "porquê" e do "para quê". O primeiro visto como atividade argumentativa de apresentar as razões que justificam determinado conteúdo, já o segundo, como atividade racional referente às finalidades abrangentes do processo formativo.

Em 1990, Veiga publica um artigo intitulado Didática: uma retrospectiva histórica, no qual afirma que as duas décadas anteriores haviam sido marcadas pela negação tanto ao verticalismo conteudista da abordagem tradicional, que visava à doutrinação religiosa (jesuítas) ou leiga (Estado Novo), quanto ao procedimentalismo da abordagem tecnicista. Segundo ela, a partir da metade da década de 1970, no início da abertura do regime político:

[...] surgiram estudos empenhados em fazer a crítica da educação dominante denominados por Saviani de "teorias crítico-reprodutivista". Movimento de saída do polo tecnicista para um polo filosófico (que será predominante na década de 80), tendo em vista um contexto de transformação social.

Sob esta ótica, a Didática nos cursos de formação de professores passou a assumir o discurso sociológico, filosófico e histórico, secundarizando a sua dimensão técnica, comprometendo, de certa forma, a sua identidade, acentuando uma postura pessimista e de descrédito relativo à sua contribuição quanto à prática pedagógica do futuro professor (VEIGA, 1990, p. 37).

O que Veiga (1990) denominou de "descaminhos da didática" brasileira, a abordagem tecnicista do período pós-1964, entra em crise com o processo de redemocratização, culminando na década de 1980. Naquele contexto, a "[...] educação desempenhava importante papel na preparação adequada de recursos humanos necessários à incrementação do crescimento econômico e tecnológico da sociedade de acordo com a concepção economicista de educação" (VEIGA, 1990, p. 35). A posterior aversão à dimensão do "como ensinar" tem sua origem na polarização abusiva do tecnicismo, que deslegitimava qualquer reflexão sobre seus fins, restringindo a validade ao procedimento racional mais eficiente: "[...] o pressuposto que embasou esta pedagogia está na neutralidade científica, inspirada nos princípios de racionalidade, eficiência e produtividade" (VEIGA, 1990, p. 35).

Conforme Veiga, o período manifesta a passagem "do polo tecnicista para um polo filosófico", na década de 1980, "tendo em vista um contexto de transformação social". Houve um ganho significativo para o campo da didática à medida que 
deixou de ser um meio de adaptação, assumindo um posicionamento crítico de diálogo com a filosofia, a sociologia e a história. Contudo, houve, também, certa perda para o campo da didática, quando deslegitimada pelo uso de um conceito reduzido de técnica, sofreu resistência em relação à sua contribuição na formação de professores.

Segundo Saviani, a teoria pedagógica de resistência crítica, da década de 1980, contribuiu para conscientizar e mobilizar as organizações sociais conforme a finalidade da redemocratização do Brasil, "mas esses ensaios não tiveram força suficiente para se impor à estrutura de dominação que caracterizava a sociedade brasileira" (SAVIANI, 2011, p. 448). Conforme o autor, o tecnicismo retornou com mais força na década de 1990, como teoria do capital humano, centrado na eficiência dos meios educativos, dispensando o caráter de fundamentação e a reflexão sobre os fins.

Em 2009, Libâneo apresentou, no III Encontro Nacional de Didática e Práticas de Ensino, um texto em que abordou os elementos constitutivos do ato didático:

Com que categorias lida a didática? Quais são os elementos constitutivos do ato didático? A análise do ato didático destaca uma relação dinâmica entre três elementos - professor, aluno, matéria - a partir dos quais são feitas as clássicas perguntas: O que ensinar? Para que ensinar? Quem ensinar? Para quem se ensina? Como se ensina? Sob que condições se ensina? (LIBÂNEO, 2009, p. 2).

O mote central é o de mediação entre esses vários componentes do ato didático. Desde a publicação do livro Democratização da escola pública, em 1986, em que Libâneo (2011) defende uma escola que não abra mão da qualidade do saber sistematizado, em outras palavras, um "o que ensinar" sociocrítico dos conteúdos. $\mathrm{O}$ autor apresenta as perguntas relacionadas aos componentes didáticos já mencionados, mas acrescenta outras. Contempla o "como se ensina", mas não deixa de fora o "para quê". Não menciona o "porquê", porém justifica a fundamentação para o entendimento do ato didático: "para cuja compreensão se juntam as teorias do ensino, as teorias do conhecimento, as ciências auxiliares da educação e a epistemologia das disciplinas ensinadas" (LIBÂNEO, 2009, p. 2). Concordo com Libâneo quando afirma que a qualidade da educação básica envolve a mediação de todos esses elementos didático-epistemológicos, sem que algum componente tenha maior ênfase do que os outros.

De modo semelhante, segue o argumento de Gatti e colaboradoras para a retomada do âmbito do "quê" e do "como" ensinar, visando a um "equilíbrio" no processo formativo curricular. Para isso, a "aplicabilidade" no ensino aparece como critério da teoria. E, de fato, a condição da melhoria procedimental é o acompanhamento da sua realização em resultados. E a validade ocorre quando se realiza a unidade 
entre teoria e prática. Entretanto, esse não pode ser um critério exclusivo de toda a teoria pedagógica, pois não daria conta da abrangência das dimensões do "porquê" e do "para quê", pois seus conceitos não se esgotam em resultados no ensino. Se esse critério fosse exclusivo, deslegitimaria o núcleo normativo da teoria pedagógica e repercutiria em todas as disciplinas de fundamentos, sobretudo, na filosofia da educação.

\section{Relação aberta entre teoria e práxis}

Além dos critérios de aplicabilidade e realização, fundamentais para a melhoria da prática procedimental, pautados na busca permanente da unidade teoria e prática, é preciso garantir também outra justificativa de validade para a dimensão da teoria conceitual normativa. Isso significa dizer que a relação teoria e prática no campo pedagógico tem um sentido duplo: por um lado, precisa pautar-se na busca da unidade, que se realiza no ensino; por outro, permanece em uma tensão aberta e dinâmica, enquanto prática normativa, orientada por fins abrangentes, condição para a viabilidade crítica do próprio processo formativo.

Aristóteles foi o primeiro pensador que sistematizou criteriosamente seu uso, diferenciando a práxis das outras duas atividades humanas básicas, a theoria e a poiésis. Assim, cada atividade - theoria, práxis e poiésis - passou a corresponder a um tipo de conhecimento: o teórico, o prático e o produtivo. O critério diferenciador é a finalidade ou o objetivo: "[...] para o conhecimento teórico, o objetivo é a verdade; para o conhecimento da poiésis, a produção de alguma coisa; e, para o conhecimento prático, a própria ação" (BOTTOMORE, 2001, p. 292).

Em Ética a Nicômaco, Aristóteles apresenta a seguinte demarcação: na theoria, a finalidade já está determinada, cabendo ao homem apenas contemplar: "aquilo que sabemos não é capaz de ser de outra forma" (ARISTÓTELES, 1979, p. 143). Já quanto à práxis e à poiésis, encontram-se no âmbito da deliberação humana: "Na classe do variável incluem-se tanto coisas produzidas como coisas praticadas", nas quais é o homem quem põe a finalidade. Contudo, existe uma diferença entre elas, pois "a capacidade raciocinada de agir difere da capacidade raciocinada de produzir [...] porque nem agir é produzir, nem produzir é agir" (ARISTÓTELES, 1979, p. 143). Na poiésis, o homem põe a finalidade fora da ação do fazer mesmo, e a atividade é um meio para outro fim, tal qual se depreende do exemplo mencionado pelo autor: a atividade de construir uma casa. Já a finalidade da práxis está na própria ação, como ocorre nos conceitos normativos da ética. Assim, a primeira se realiza (termina enquanto meio) no resultado da obra (a casa), que, por sua vez, tem outro fim, ser habitada; ao passo que, na práxis, 
a finalidade repõe-se continuamente em si e por si mesma (a boa ação em geral). Portanto, as origens do conceito de práxis já apontam seu caráter normativo de finalidade humana abrangente em si mesma, desautorizando sua mera instrumentalização.

Para Dalbosco, essa demarcação proposta por Aristóteles pode contribuir significativamente para o campo pedagógico, compreendido como âmbito da racionalidade da práxis, o conceito de prática pedagógica não pode ser compreendido apenas como um mero fazer produtivo, pautado pela relação meio-fim, quando a finalidade é externa ao fazer. A partir dessa diferenciação, é possível pensar em desdobramentos para a relação entre professor e aluno em sala de aula.

Cogitar tal relação no contexto da racionalidade da práxis implica, por exemplo, que tanto professor como aluno não possam tomar um ao outro como meio para alcançar determinados fins, isto é, a relação entre ambos não deve ser concebida nos moldes de uma ação produtora que tenha a finalidade somente externa à ação, mas não como uma ação agente, que encontre nela mesma a sua finalidade. Sem este aspecto intrínseco, a ação pedagógica não pode alcançar uma condição autônoma, permanecendo, por isso, uma ação heterônoma. Já a partir de Aristóteles, podemos entender a pedagogia, portanto, não simplesmente como uma técnica, mas principalmente como uma das diferentes formas da práxis humana (DALBOSCO, 2007, p. 45-47, grifo do autor).

Mesmo a interpretação marxiana de práxis é orientada por um conceito normativo de emancipação. De fato, nos Manuscritos econômico-filosóficos, o conceito de práxis tem sua gênese no trabalho humano. Seus contornos surgem à medida que Marx amplia materialmente o conceito hegeliano de objetivação. Na condição de atividade sensível, o homem tanto transforma a natureza, para satisfazer suas necessidades, como cria a si mesmo. Enfim, a objetivação realizada pelo trabalho é a unidade (síntese) mais próxima e mais profunda entre o ser humano e a natureza. $\mathrm{E}$ a práxis, que daí surge, tem caráter de unidade e de reconhecimento entre subjetividade e objetividade. Desde sua gênese, o ponto de partida da práxis é a atividade reflexiva para satisfazer as necessidades mais basilares do ser humano, porém vai muito além delas, visto que sua potencialidade é a capacidade de extrapolar até atingir a consciência do seu ser social.

No entanto, o conceito de práxis conquista centralidade no pensamento de Marx, a partir do debate sobre o conceito da emancipação humana. Segundo Schimied-Kowarzik, desde os primeiros escritos, "[...] a partir do confronto crítico com Hegel, até a obra madura, que ficou incompleta, na Crítica da Economia Política, a filosofia de Marx viu-se ligada aos fins da emancipação humana” (2002, p. 49). A práxis marxiana nasceu no âmago da crítica da emancipação e dela não pode ser desvinculada para evitar a instrumentalização do próprio conceito. 
Por sua vez, sem o conceito normativo da emancipação social não seria possível a crítica ao trabalho alienado. No capítulo Trabalho estranhado, o ponto de partida da análise é: "O trabalhador se torna tanto mais pobre quanto mais riqueza produz". A pobreza em questão não significa apenas a perda econômica, pois o trabalho "produz beleza, mas deformação para o trabalhador" (MARX, 2004, p. 82) e "arruína seu espírito" (MARX, 1989, p. 162). A perda refere-se à promessa de liberdade e da autorrealização, conforme o projeto de emancipação da modernidade.

Ao contrário disso, por alienação/estranhamento o autor compreende como a dimensão negativa do trabalho, quando, por razões históricas e sociais, o humano não se reconhece nas suas próprias obras, nem se reconhece como particularidade constitutiva da universalidade do ser social. Portanto, a práxis que aparece nas Teses sobre Feuerbach, que visa atingir à unidade teoria e prática, tem um sentido social e político abrangente. Trata-se de um horizonte conceitual normativo, na qual todo ser humano, e toda a humanidade, deixaria de ser mero meio produtivo para ser um fim em si mesmo. Esse parece ser o pressuposto da afirmação: "É na práxis que o homem deve demonstrar a verdade" (MARX, 2000, p. 108). Desvincular o conceito do referido horizonte, buscar a unidade tão somente de curto alcance, apenas contribuiria para conservar e aumentar a eficiência do existente; logo, sentido contrário do seu caráter crítico e transformador.

Para Adorno e Horkheimer (1985), depois dos eventos catastróficos do século XX, possibilitados pelo desenvolvimento de uma razão predominantemente instrumental, a postura mais. É verdade que a sociedade precisa desses resultados para se reproduzir, mas essa unidade é restrita ao existente. Então, "deve, portanto, considerar um momento de unidade entre teoria e prática, na realização da história, mas, principalmente, uma separação necessária entre elas, para que a contingência possa ser criticamente refletida" (VAZ, 2002, p. 426, grifo do autor). Sob tal perspectiva, é possível pensar uma dupla relação entre teoria e prática: a de unidade, com ênfase na realização de resultado, porém restrita, e a de tensão aberta, que não se realiza plenamente, mas possibilita a crítica e a autocrítica.

Persistir na relação de tensão aberta pressupõe a compreensão "que não separasse ambas de modo que a teoria fosse impotente e a práxis arbitrária, nem destruísse a teoria mediante o primado da razão prática” (ADORNO, 1995, p. 204). Sem dúvida, é ilusória a ideia de autonomia absoluta da teoria, porque ela já é produto da sociedade. De outro modo, não se restringe apenas em uma relação de identidade, pois pode gerar o distanciamento conceitual dessa, margem para a autonomia crítica. Mesmo na condição de tensão, ela ocorre dentro de uma 
unidade, porém não necessariamente se realiza em uma síntese. Portanto, existe um duplo caráter da teoria social: ela é pertencente à sociedade e, ao mesmo tempo, é autônoma.

Como desdobramento ao campo educacional, pode-se dizer que a teoria pedagógica também apresenta esse caráter: reproduz a sociedade e, igualmente, é formadora de autonomia. Assim, a relação teoria e prática apresenta dois sentidos: por um lado, visa à unidade de identidade na realização do ensino; por outro, busca promover uma tensão aberta entre elas como viabilidade crítica ao processo de formação cultural. Portanto, a melhoria precisa garantir a qualidade nos dois sentidos, pois são diferenciados e interdependentes. Preservar, na teoria pedagógica, um núcleo com legitimidade em si mesmo garante certa autonomia às áreas de fundamentos.

\section{Considerações finais}

A pesquisa diagnóstica dos cursos de pedagogia analisada neste texto está focada em um conceito de prática procedimental, por isso estabelece como parâmetro da teoria a aplicabilidade e a realização. De fato, concordo que tal critério possa contribuir para a melhoria do ensino. Há razão, porém, até certo ponto, uma vez que não avança em direção à complexidade da formação cultural. Em outras palavras, tal critério não pode ser considerado exclusivo, pois abarca apenas uma parte da teoria pedagógica. Portanto, além de considerar a importância do resgate da relação que visa à unidade de identidade teoria e prática, condição necessária para a melhoria do fazer ensino, o desafio é garantir também um âmbito de relação de tensão aberta, necessário ao processo de formação cultural. Preservar e justificar racionalmente, na teoria pedagógica, um núcleo que tem a legitimidade em si mesmo é o pressuposto básico das áreas de fundamentos. É nessa atividade que a filosofia da educação encontra seu lugar formativo. 


\section{Philosofy of education: conceptual critical considerations to the educational reform of the courses of pedagogy}

\section{Abstract}

This study develops critical considerations to the concepts of theory and practice as they appear in the diagnostic evaluation of the educational reform in courses of Pedagogy. The analysis starts from the verification that the courses have failed in the practical training. It disagrees with applicability as a criterion for validating the theory. It acknowledges that it is appropriate to the improvement of "what" and "how to teach", but should not be exclusive, because it would reduce pedagogical theory only to its teaching aspects. It implies in instrumentalizing or relegating the theoretical foundations to a less important place, among them the Philosophy of Education. It is necessary to justify a broader concept of practice, which ensures the legitimacy of an autonomous nucleus of theory. By doing so, it seeks to argue in favor of the dual character of the theory: it belongs to society and is autonomous. Pedagogical theory also reproduces society and resists to it as a cultural formation. Therefore, the relationship with practice presents two meanings: it aims to the unity of identity in teaching and also to a nucleus of tension opened to criticism and self-criticism.

Keywords: Educational reform. Theory and praxis. Philosophy of education.

\section{Notas}

1 Este texto tem embasamento em trechos desenvolvidos na minha tese de doutorado, principalmente do primeiro capítulo, submetida ao Programa de Pós-Graduação em Educação da Universidade Federal de Santa Catarina, com o título Dos lugares da filosofia da educação: reforma educacional, praticismo, formação, Orientador: Prof. Dr. Alexandre Fernandez Vaz, (VOLOSKI, 2013).

2 Fundo de Manutenção e Desenvolvimento do Ensino Fundamental e de Valorização do Magistério, instituído pela Emenda Constitucional n⿳ำ 14, de setembro de 1996, e regulamentado pela Lei n. 9.424 , de 24 de dezembro do mesmo ano, e pelo Decreto nº 2.264, de junho de 1997.

3 Fundo de Manutenção e Desenvolvimento da Educação Básica e de Valorização dos Profissionais da Educação, criado pela Emenda Constitucional nº 53/2006, regulamentado pela Lei nº 11.494/2007 e pelo Decreto $\mathrm{n}^{\mathrm{0}} 6.253 / 2007$, em substituição Fundef, que vigorou de 1998 a 2006.

4 Oportunamente, ressalto que é observável, em diferentes momentos, na Resolução CNE/CP nº 1/006, que estabelece as diretrizes curriculares aos cursos de pedagogia, a tentativa de garantir um conceito amplo de prática. Para exemplificar, no art. 3, encontra-se a seguinte redação: "fundamentando-se em princípios de interdisciplinaridade, contextualização, democratização, pertinência e relevância social, ética e sensibilidade afetiva e estética"; no art. 5, "identificar problemas socioculturais e educacionais com postura investigativa, integrativa e propositiva em face de realidades complexas [...]”, no art. 6º "atenção às questões atinentes à ética, à estética e à ludicidade" (BRASIL, 2006, p. 1-2, 4).

5 De acordo com Dalbosco: "Tendências mundiais parecem indicar para um recuo da reflexão sobre pressuposições ético-epistemológicas da educação. A área dos fundamentos da educação vem há mais tempo perdendo terreno para as didáticas específicas. Essa diretriz tende a acentuar-se, no momento, pela direção que o Plano Nacional de Formação de Professores parece tomar, focalizando a formação no 'que' e no 'como' ensinar, secundarizando a importância de questões que tradicionalmente caíam sobre o âmbito dos fundamentos, como 'para que educar' ou 'para que educação' (Wozu Erziehung?). Desse modo, a didatização da educação ocorre mediante o enfraquecimento de uma perspectiva normativa e teológica da educação" (2010, p. 179-180). 


\section{Referências}

ADORNO, Theodor. Palavras e sinais: modelos críticos. Petrópolis: Vozes, 1995.

ADORNO, T.; HORKHEIMER, M. Dialética do esclarecimento: fragmentos filosóficos. Rio de Janeiro: Jorge Zahar, 1985.

ARISTÓTELES. Ética a Nicômaco. São Paulo: Abril Cultural, 1979. (Coleção Os pensadores).

BOTTOMORE, Tom et al. Dicionário do pensamento marxista. Rio de Janeiro: Jorge Zahar, 2001.

BRASIL. Lei de Diretrizes e Bases da Educação Nacional. Lei n. 9.394/96, de 20 de dezembro de 1996.

Ministério da Educação. Conselho Nacional de Educação. Resolução n⿳o 01, de 18 de fevereiro de 2002. Diretrizes Curriculares Nacionais para a Formação de Professores da Educação Básica, licenciatura. Brasília, 2002.

. Ministério da Educação. Conselho Nacional de Educação. Resolução no 1, de 15 de maio de 2006. Diretrizes Curriculares Nacionais para o Curso de Graduação em Pedagogia, licenciatura. Brasília, 2006.

CASTRO, A. D. de. A trajetória histórica da didática. Ideias, São Paulo, n. 11, p. 17-27, 1991.

DALBOSCO, Claudio Almir. Pedagogia filosófica: cercanias de um diálogo. São Paulo: Paulinas, 2007.

Pragmatismo, teoria crítica e educação: ação pedagógica como mediação de significados. Campinas: Autores Associados, 2010.

GATTI, Bernardete; NUNES, Marina. Formação de professores para o ensino fundamental: estudo de currículo das licenciaturas em pedagogia, língua portuguesa, matemática e ciência biológica. São Paulo: FCC/DPP, 2009.

GATTI, Bernardete A. et al. Avaliação dos currículos de formação de professores para o ensino fundamental. Estudos em Avaliação Educacional, São Paulo, v. 20, n. 43, maio/ago. 2009. Disponível em: <fcc.org.br/pesquisa/publicações>. Acesso em: 10 set. 2009.

LIBÂNEO, José Carlos. A didática e as exigências do processo de escolarização: formação cultural e científica e demandas das práticas socioculturais. In: EDIPE - ENCONTRO NACIONAL DE DIDÁTICA E PRÁTICA DE ENSINO, 3, 2009, Anápolis, GO. Anais... Anápolis, 2009. Disponível em: <http://docslide.com.br/documents/a-didatica-e-as-exigencias-do-processo-de-escolarizacao.html\#>. Acesso em: 5 out. 2016.

. Democratização da escola pública. A pedagogia crítico-social dos conteúdos. 26. ed. São Paulo: Loyola, 2011.

MARX, Karl. Manuscritos econômico-filosóficos. Lisboa: Edição 70, 1989. . Manuscritos econômico-filosóficos. São Paulo: Boitempo, 2004.

2000. . Teses sobre Feuerbach. In: GIANOTTI, J. A. Marx: vida e obra. Porto Alegre: L\&PM, 
NOBRE, Marcos. A teoria crítica. Rio de Janeiro: Jorge Zahar, 2004.

2011. . História das ideias pedagógicas no Brasil. 3. ed. rev. Campinas: Autores Associados,

SCHIMIED-KOWARZIK, Wolfdietrich. Práxis e responsabilidade. Porto Alegre: EdiPUCRS, 2002.

TREVISAN, A. L. Filosofia da educação e formação no velho dilema entre teoria e prática. Educar em Revista - UFPR, Curitiba, n. 42, p. 195-212, out./dez. 2011.

VAZ, Alexandre Fernandez. Notas sobre a relação teoria e prática em Antônio Gramsci e Theodor W. Adorno e Max Horkheimer. Perspectiva, Florianópolis, v. 20, n. 2, p. 425-442, jul./dez. 2002.

VEIGA, Ilma Passos A. Didática: uma retrospectiva histórica. In: VEIGA, Ilma P. A. (Org.). Repensando a didática. Campinas: Papirus, 1990. p. 25-40.

VOLOSKI, Gilson L. Dos lugares da filosofia da educação: reforma educacional, praticismo, formação. 2013. Tese (Doutorado em Educação) - Programa de Pós-Graduação em Educação, Universidade Federal de Santa Catarina, Florianópolis, 2013. 